\title{
Conditional Indexation in Defined Benefit Pension Plans in the Netherlands*
}

\author{
Jacob A. Bikker ${ }^{\mathrm{a}}$ and Peter J.G. Vlaar ${ }^{\mathrm{b}}$ \\ ${ }^{a}$ De Nederlandsche Bank (DNB), Supervisory Policy Division, Strategy Department, P.O. Box 98, \\ Amsterdam, $1000 \mathrm{AB}$, The Netherlands. \\ E-mail: j.a.bikker@dnb.nl \\ ${ }^{\mathrm{b}}$ De Nederlandsche Bank (DNB), Economics and Research Division, Financial Research Department, \\ P.O. Box 98, Amsterdam, 1000 AB, The Netherlands. \\ E-mail: p.j.g.vlaar@dnb.nl
}

In an ageing society, defined benefit (DB) pension plans are increasingly difficult to manage by means of contribution policy only, as the contribution base is likely to shrink relative to total pension provisions. This development, together with an increased emphasis on market valuation in regulatory and accounting rules, has led to a switch of DB plans to defined contribution plans throughout the world. In the Netherlands, a different solution has been sought. The typical pension contract nowadays comprises an average earnings DB pension in which only nominal benefits are guaranteed, but with the intention to provide wage or price indexation. In the new supervisory regime, the guaranteed pension rights, based on market valuation, are subject to risk-based solvency requirements. Provisioning is not required for conditional pension rights, although contributions have to be consistent with the indexation ambition. In this paper, we analyse to what extent indexation is indeed likely, given various indexation and contribution policies. Simulations show that voluntary provisioning for indexation is to be recommended. Fully guaranteed indexation is virtually unaffordable under the new supervisory regime, because the real discount rate is generally both very low and highly volatile.

The Geneva Papers (2007) 32, 494-515. doi:10.1057/palgrave.gpp.2510140

Keywords: average wage defined benefit pension; Monte-Carlo simulations; pension fund model; regulation; wage or price indexation

\section{Introduction}

An inflation-proof pension scheme is a very valuable asset for pension fund participants. Generally, only inflation-proof pensions can protect them from financial insufficiency after retirement. ${ }^{1}$ The provision of insurance against wage or price

\footnotetext{
* The authors wish to thank two referees of this journal, as well as Dirk Broeders, Peter van Els, Lex Hoogduin, Aerdt Houben, Klaas Knot and Gaston Siegelaer for their useful contributions. Views expressed are those of the authors and do not necessarily reflect official positions of the Nederlandsche Bank.

${ }^{1}$ Summers (1983), on the other hand, claims that indexation guarantees in pension contracts will generally not be efficient as pension beneficiaries are much better hedged against inflation risk, for instance due to home ownership, than are the bearers of pension liabilities. Assuming total compensation for employees
} 
inflation based on intergenerational risk sharing is even considered an important reason for the existence of defined benefit (DB) pension funds. ${ }^{2}$ In the Netherlands, indexation of pension benefits to either wage or price increases has long been considered a guaranteed right. Although indexation used to be conditional on the pension fund's financial position, in practice full indexation was virtually always awarded. In the communication to pension beneficiaries the possibility of indexation cuts was not given much attention. The adverse stock market returns during 2000-2002 have radically changed this perception and the practice of automatic indexation, as many pension funds became severely underfunded. In order to recover, not only were pension contributions increased firmly, but indexation was reduced as well. Moreover, many pension arrangements were renegotiated and, as a result, turned from a conditional DB final wage system to a conditional DB average earnings scheme. Consequently, indexation cuts can not only be applied to pensioners but also to active workers. ${ }^{3}$

Although the stock market crash certainly triggered the increased use of indexation cuts, other developments also contributed to decreased security regarding indexation. First, both nominal and real interest rates have dropped considerably over the last decade. These low interest rates imply lower expected future returns, raising the discounted costs of future pension benefits. Under the previous regulatory regime, effective until end-2006, the maximum allowed actuarial interest rate, used to calculate the level of contributions and the funding ratio of the fund, remained constant at 4 per cent. Therefore, the gradual deterioration of the funding position was not well detected and contributions had decreased far below the cost-covering level. A second, though related, reason for the pension funds' financial weakness is the gradual change in the investment portfolio of pension funds. With the decline in (real) interest rates, a bond-dominated portfolio no longer guaranteed sufficient returns to safeguard indexation, given the contribution level. One of the responses of pension funds was to invest more in the stock market, which not only increased average returns but also the risk. A third reason for growing uncertainty regarding indexation is the recent change in international accounting rules (IFRS). Companies with DB pension plans are obliged to report the assets and liabilities of their pension fund on their own balance sheet. As this increases the volatility of their results, companies become more in favour of defined contribution (DC) schemes. So far, the number of Dutch firms offering genuine DC pension plans is still negligible however. Finally, the ageing of the population increases the ratio of pension liabilities to the total wage bill. Consequently, the contribution instrument will become less effective to absorb adverse developments.

is equal to their marginal productivity (Sharpe, (1976)), such inefficiencies also reduce welfare for workers.

2 Ponds (2003).

${ }^{3}$ Because indexation of pension benefits is only awarded if the financial position of the fund allows it, the Dutch system is hybrid rather than pure DB. It combines a DB nominal pension with Targeted Benefit indexation. Although in this system the employees bear some risk, the term conditional DB is more apposite than DC, since contributions are not fixed whereas (maximum) benefits are clearly defined. 
Partly in response to the changing environment, at the end of the 1990s the Dutch supervisor of pension funds started the development of a new supervisory regime. In early 2007, this new Financial Assessment Framework (Financieel Toetsings Kader, FTK) has become effective. A dilemma in designing such a supervisory framework is that, on the one hand, it should be strict enough to safeguard the solvency of relatively weak funds, but, on the other, it should not be too restrictive, as this might induce excess volatility or interfere with the optimal policy of a fund. Moreover, overly strict rules might induce pension fund sponsors to change the pension contract, for example, reduce guarantees or even switch to DC. In the U.K. for instance, the increased burden of regulation since the mid-1980s has led to the closure of most private DB schemes to new entrants. ${ }^{4}$ In the FTK, a balance is sought by prescribing relatively strict solvency requirements for guaranteed (in practice, nominal) pension rights, whereas much more flexibility is given regarding conditional rights (such as indexation). For guaranteed rights, the new regulatory regime is in line with modern finance views in the sense that market valuation is not only applied to assets but also to liabilities, and that more risk taking results in higher required buffers. Guaranteed commitments should always be fully funded, including risk-related buffers to protect against adverse developments. For conditional rights, provisioning is not required, although pension contributions and policies have to be consistent with communicated indexation ambitions. ${ }^{5}$ Pension funds are required to disclose their indexation ambitions to their members, including a realistic estimate of the likelihood of success in pursuing this ambition. In addition, pension funds have to ensure consistency between expectations raised, financing, reserves and actual indexation decisions. Like the FTK in general, these rules impose minimum requirements or constraints without making explicit recommendations regarding pension funds' policies.

The purpose of this paper is threefold. First, it investigates to what extent the new Dutch regulatory regime does indeed achieve greater clarity with respect to indexation ambitions. Second, it analyses whether and to what degree FTK's minimum requirements can provide reasonable security that indexation ambitions will be realised. And third, it assesses whether the FTK regime is too restrictive on funds that already pursue sound policies. These questions are analysed with the help of the Pension Asset and Liability Model for the Netherlands, named Palmnet. ${ }^{6}$ The results illustrate how intergenerational risk sharing in conditional DB pension plans can still provide a reasonable insurance of pension benefits against wage or price inflation, also under difficult conditions such as ageing, the new accounting and regulatory regimes, both based on fair-value and volatility on financial markets. The main caveat is, however, that the analysis is only partial. There is no discontinuity risk in the model, and the above cost-covering contributions are assumed to have no labour market repercussions.

\footnotetext{
${ }^{4}$ Davis (2004).

${ }^{5}$ This outcome was a compromise between the government, employees and employers. As most pension funds were heavily underfunded in real terms at the end of 2002, stricter rules regarding conditional rights were unacceptable for the social partners, as such rules would have led to either excessive rises in contribution or cut backs on vested pension rights.

${ }^{6}$ Van Rooij et al. (2004).
} 
The structure of this paper is as follows. The following section provides an overview of the three-pillar pension system prevailing in the Netherlands and explains the main principles of the new minimum supervisory requirements laid down in the FTK. The next section describes the main features of the Palmnet model. The penultimate section gives the outcome of the Palmnet simulations, showing probability distributions of the results over time for each of the model's key variables. The final section summarises and concludes.

\section{Pension schemes in the Netherlands}

The Dutch old age pension system may be compared with a three-pillar rocket. The first pillar is a national insurance scheme (called AOW), which provides a basic pension for every person over 65, irrespective of one's wealth or other income sources. AOW benefits are financed according to the pay-as-you-go method. The second pillar consists of mandatory company-wide or industry-wide pension schemes for employees for a pension in addition to the AOW benefit. This pillar of the Dutch pension scheme is funded and covers almost all employees. The third pillar comprises savings schemes of life insurance firms, which people arrange individually. The second and third pillar savings benefit from tax privileges, provided certain conditions are met.

At the end of 2006, the Netherlands had 767 pension funds under supervision by the Dutch Central Bank (of which 643 are company pension funds and 103 are industrywide pension funds). In that year, they managed $€ 680$ billion in pension capital (129 per cent of GDP). Besides pension funds, life insurance companies directly manage about one-sixth of the second pillar pension schemes. In 2005, gross contributions to pension funds added up to 25 billion, whereas their pension benefits amounted 18 billion, against annual AOW payments of 23 billion. Participation in the pension scheme offered by the employer is compulsory for each employee by law. Pension contributions are spread over employer and employee, where the employer usually takes most of the burden.

Almost all pension schemes managed by pension funds are of the (conditional) DB type (99 per cent), ${ }^{7}$ whereas insurance companies primarily (71 per cent) offer DC schemes. Most DB pension contracts guarantee only a nominal pension, but price or wage indexation is aimed for. In recent years, we observe a gradual move from final pay pension schemes to average earnings schemes. In an average earnings scheme, a person's pension benefits are linked to the salary at the moment contributions are paid, whereas in a final pay scheme the benefits are related to the last-earned salary. The average earnings schemes make it easier to control the cost of pension contributions, as adjustments of benefits to wage or price inflation can be reduced (also for active workers) when pension capital is insufficient. Moreover, there is no need to increase existing pension benefits in the case of career moves (the so-called "back service").

\footnotetext{
${ }^{7}$ Currently, a number of pension funds consider a shift from DB to (collective) DC, primarily in response to changes in international accounting standards (IFRS).
} 
Internationally, the Dutch system of old age provision is quite unique. Only few countries have saved for their second pillar pensions in a comparable manner via a compulsory fully funded system and cover almost all employees. In the U.K. and the U.S., countries that have also built up a substantial pension capital (in percentage points of GDP) through funding schemes, DC schemes dominate the market and their proportion is increasing. ${ }^{8}$

The decline in share prices during 2000-2002 has revealed that pension liabilities of some Dutch pension funds were not covered sufficiently by pension capital to be able to overcome protracted unfavourable market developments. The prolonged decline in long-term bond rates towards historically low levels also challenges the solvency of pension funds. Until end-2006, the pension liabilities were calculated on the basis of a fixed actuarial interest rate of at most 4 per cent (a number that had not changed since 1969), which was considered a conservative estimate of the expected long-run real return on the asset portfolio. Under FTK, the fixed actuarial interest rate to calculate liabilities is replaced by the (nominal) market rate.

The FTK distinguishes sharply between guaranteed (which in practice means: nominal) pension entitlements and conditional rights (indexation linked to wage or price inflation). Pension funds only have to provision for unconditional pension liabilities, with the size of the mandatory provisions based on those liabilities' current market value. ${ }^{9}$ If, due to adverse circumstances, the funding ratio (i.e., the ratio between a fund's assets and its mandatory provisions) falls below 105 per cent, this rate has to be restored by some means or other, under normal conditions within 1 year. This may be done by (a combination of) reducing or eliminating indexation, increasing contributions, receiving a subordinate loan or by renegotiating the unconditional rights (between the management and trade unions). In exceptional circumstances, the supervisor can allow for a longer recovery period. ${ }^{10}$

The nominal funding ratio must, in principle, be sufficient to maintain a less than 2.5 per cent probability of insolvency (defined as a nominal funding ratio below 100 per cent) within 1 year. For an average pension fund, this implies a target nominal funding ratio of at most 130 per cent. If the nominal funding ratio falls below this minimum, a recovery plan must be implemented (consisting of extra contributions and/or indexation cuts) that redresses the shortfall within the next 15 years.

Provisioning for conditional pension rights (e.g., indexation) is not mandatory, as long as full consistency between ambition, expectations raised and actual indexation decisions is preserved. By means of a so-called continuity analysis, funds should explain to their members what the long-term outlook for indexation exactly is.

Pension funds should levy the so-called cost-covering contribution including normal costs of guaranteed rights, administrative costs, normal costs of conditional rights and

${ }^{8}$ Blake (2000).

${ }^{9}$ For pension funds providing a nominal guarantee only, this value is calculated by discounting expected future benefits against the current nominal-term structure of interest rates. If an additional indexation guarantee has been given, the real interest rate-term structure must be used.

${ }^{10}$ With the passing of the new Pension Law, in effect from early 2007, the original 1-year recovery plan was replaced by a 3 -year one. Under certain conditions, however, the supervisor may still require a 1-year plan. In this study, a standard 1-year recovery plan is assumed. 
costs to build up the solvency buffer. The actual contribution will generally be higher if the buffer is too small. Contributions below cost-covering level are only allowed if the funding ratio is high enough to guarantee both conditional and unconditional pension rights without endangering the solvency of the fund. To calculate the contribution, pension funds can either use actual market rates, a moving average of past market rates and/or portfolio returns with a maximum smoothing period of 10 years, or a fixed rate. The use of expected returns, rather than the real term structure of interest rates to calculate cost-covering contributions, can be justified by the fact that indexation is not guaranteed. Smoothing or fixing is allowed for in order to mitigate the volatility of contributions.

\section{The Palmnet model}

We use the model Palmnet to evaluate a range of pension fund policies with increasing levels of indexation ambition. Palmnet is a model of the average Dutch pension fund, assuming an average earnings DB system. This model describes future pension fund behaviour in a stochastic setting. The view that stochastic simulation models are an invaluable tool for pension funds has long been recognised. Early examples are Wilkie $^{11}$ for the U.K. and Boenders ${ }^{12}$ for the Netherlands. In Palmnet, the inflation rate, interest rates and stock market returns are stochastic variables. Interest rates are based on a two-factor term structure model, where the factors are the short-term nominal interest rate and expected inflation (see Appendix). Each year, the expected stock market return is 3 percentage points higher than the prevailing 5-year interest rate, with a volatility of 15 per cent annually. Stock market shocks are assumed not to be correlated with inflation or interest rate shocks. Economic theory provides various causal relationships between these variables, although some result in positive correlations whereas others cause negative correlations. Empirical estimates of these correlations are not significantly different from zero. Note also that Dutch pension funds have worldwide investments, whereas inflation is a purely domestic phenomenon.

Regarding the pension contract, only the nominal part of the benefits is guaranteed, although the ambition is to index benefits to wage inflation, in line with common practice in the Netherlands. ${ }^{13}$ In order to reflect both the nominal guarantee and the conditional indexation ambition, the pension fund policy regarding contributions and indexation is assumed to depend both on the nominal and the real funding ratio. For relatively low funding levels, the minimal requirements for the nominal funding ratio become binding, whereas policy is determined by the total ambition (reflected in the real funding ratio) in case of sufficient funding.

Table 1 shows the standard policy ladders used in Palmnet. The critical nominal funding ratio of 124.5 per cent is calculated such that the probability of insolvency in the next period is exactly 2.5 per cent, given the assumed model parameters and the

\footnotetext{
${ }^{11}$ Wilkie $(1986,1995)$.

12 Boenders (1997).

${ }^{13}$ An alternative such as indexation linked to price inflation is also possible.
} 
The Geneva Papers on Risk and Insurance - Issues and Practice

500

Table 1 Standard policy ladders used in palmnet

\begin{tabular}{|c|c|}
\hline Funding ratio (in \%) & Indexation \\
\hline Under 105 (nominal) & No indexation \\
\hline 105 (nominal) - 105 (real) & Indexation cut declines linearly \\
\hline $105($ real $)-120($ real $)$ & Full indexation, no compensation for previous cuts \\
\hline \multirow[t]{2}{*}{ Over 120 (real) } & Full indexation, with compensation \\
\hline & Contributions \\
\hline Under 105 (nominal) & $\begin{array}{l}\text { Based on a } 1 \text {-year recovery plan, maximum increase } \\
10 \text { percentage points per annum }\end{array}$ \\
\hline Under 124.5 (nominal) or 110 (real) & $\begin{array}{l}\text { Based on } 15 \text {-year recovery plan, no reduction, maximum } \\
\text { increase } 3 \text { percentage points }\end{array}$ \\
\hline $110($ real $) / 124.5$ (nominal) $-120($ real $)$ & Actual cost, maximum annual change 3 percentage points \\
\hline $120($ real $)-140$ (real) & $\begin{array}{l}\text { Linear reduction of contribution to zero, maximum annual } \\
\text { change } 3 \text { percentage points }\end{array}$ \\
\hline 140 (real) - 175 (real) & Zero contribution (or 3 percentage points lower than last year) \\
\hline Over 175 (real) & Contribution restitution \\
\hline
\end{tabular}

Notes: Nominal funding ratios are based on the actual nominal term structure of interest rates. Real funding ratios and contributions are usually based on a fixed discount rate equal to the expected long-run real return (3.06 per cent).

representative asset mix with 50 per cent bonds (average duration 6 years) and 50 per cent equity. A real target funding ratio of 110 per cent is actively pursued in order to keep the pension contract attractive to new entrants, even after adverse return developments. The on average lower pension contributions resulting from higher financial buffers compensate for the relatively high contribution volatility due to the ageing society.

In order to preserve the long-run perspective of pension funds, contributions and real funding ratios are calculated based on a fixed discount rate equal to the expected long-run real return on a representative portfolio (3.06 per cent). ${ }^{14}$ This approach greatly reduces contribution volatility. ${ }^{15}$ It is validated by the fact that indexation is only conditional and not guaranteed. Contribution volatility is further reduced by assuming a maximum annual contribution change of 3 percentage points of the contribution base (about 1.8 percentage points of gross wages), except in case of nominal underfunding (maximum increase is 10 percentage points of the contribution base) or restitutions (no limit). In all cases, it is assumed that pension contributions cannot be higher than 50 per cent of the contribution base (about 30 per cent of gross wages). As there are also pension funds with weaker (or no) indexation ambition, and as provisioning for conditional indexation is not obligatory, Palmnet can also be run without 15-year recovery plans in case of a real funding ratio below 110 per cent. In accordance with the FTK, contributions can also be based on actual current or

\footnotetext{
${ }^{14}$ Enlarging the share of equities does not necessarily raise the discount rate, because the discount rate applied within Palmnet is generally based on a representative, not the actual portfolio.

${ }^{15}$ Van Rooij et al. (2004); Vlaar (2005).
} 
smoothed interest rates. In a pre-FTK version of the model, the nominal funding ratio has no impact on the contribution policy.

In order to calculate pension liabilities, Palmnet keeps track of old age pension rights built up per separate 1-year age group. Each year, these pension rights are reduced due to mortality and possibly increased due to indexation. New pension rights are based on the expected number of workers in each age group, based on macro projections regarding total population (according to Statistics Netherlands) and labour market participation. ${ }^{16}$ This way, the impact of the ageing society on the average pension fund is automatically included. The projected ratio of total pension liabilities to the contribution base increases from about 5 in 2002 to 9.5 in the second half of this century. Given pension rights per age group, expected future benefit payments, based on life tables, are discounted using the actual nominal term structure of interest rates (nominal funding ratio), respectively using the fixed real discount rate (real funding ratio).

\section{Simulation results}

Within the framework of the FTK, pension funds should make at least three crucial decisions with respect to indexation: (a) the level of indexation ambition; (b) whether indexation is guaranteed or conditional; and (c) in the case of conditional indexation, whether voluntary provisions are made which are earmarked for indexation.

Following these three criteria, we simulate results under the FTK regime for four different hypothetical pension funds with increasing indexation ambition. The first fund makes no explicit indexation commitments, although indexation is given (up to full wage indexation) if sufficient capital is available. The second fund announces an ambition to index pensions to wages, but does not pursue an explicit policy to build up reserves for this. However, contributions do reflect this ambition. The third fund has the same ambition, and, moreover, an explicit strategy to maintain an adequate provision for this ambition. The fourth fund is even more ambitious as indexation is guaranteed. These simulations are compared to a variant prepared with a baseline version of Palmnet, where the nominal funding ratio has no impact on the contribution policy (i.e., without the FTK requirements).

Simulations start off from the situation applying to the average pension fund at the end of 2002. The pension wealth evaporated during the turn of the century needs to be replenished, on top of the pension provisions in the equilibrium situation. Simulation results will of course be even worse for a pension fund whose initial financial position is even less favourable. For 2003 and later, the results were simulated. With respect to the asset mix, the choice of the average pension fund with 50 per cent equity and 50 per cent bonds was assumed in all simulations. As in practice, the average bond duration is taken to be 6 years, even though a higher bond duration might be beneficial for pension funds. ${ }^{17}$

\footnotetext{
${ }^{16}$ According to Van Ewijk et al. (2000).

17 Vlaar (2005).
} 

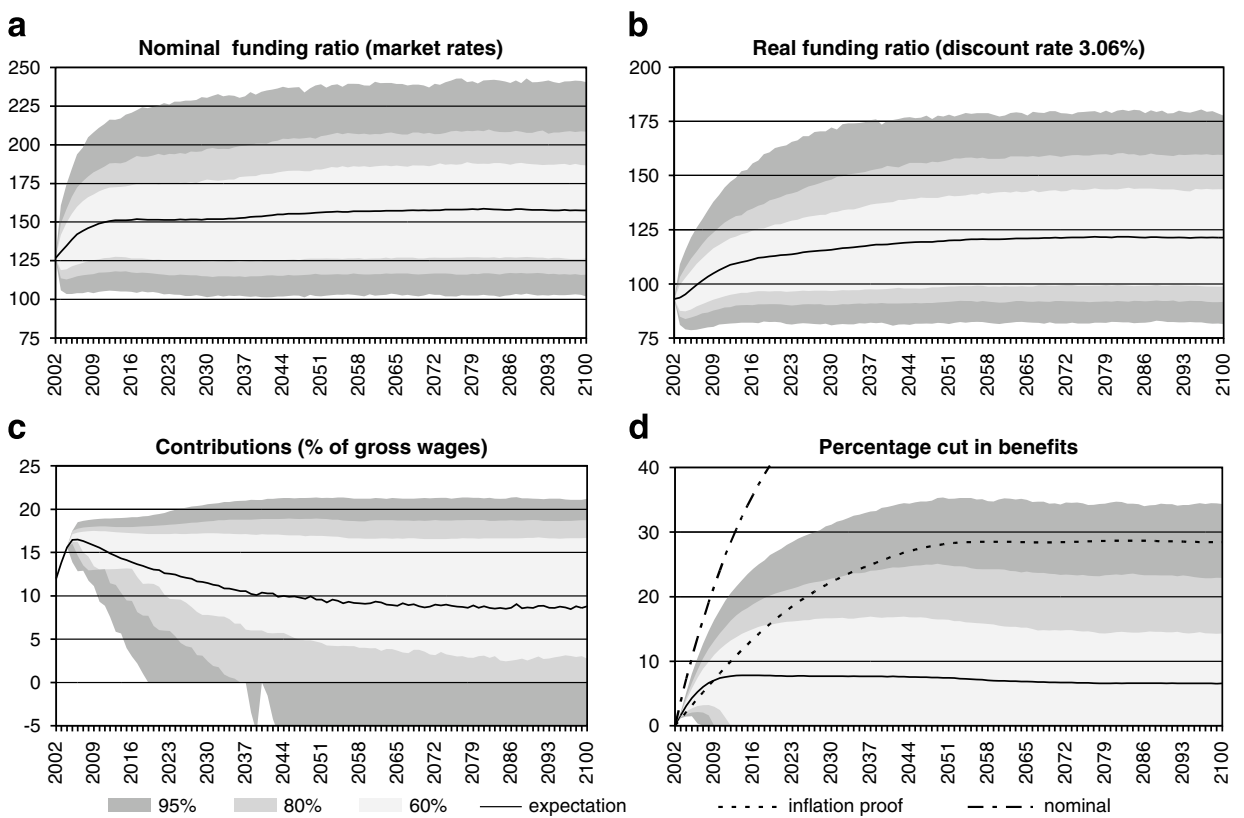

Figure 1. Base variant, no impact of nominal funding ratio on contributions.

The results are presented in graphical form (Figures 1-5), whereas some key features are summarised in Table 2. The figures give an impression of the development over time of the entire distribution of the nominal and real funding ratios (Panels a and $b$ ), the contributions as a percentage of gross wages (Panel c), and the cut in benefit for the average pensioner relative to a fully wage-indexed pension (Panel d). Apart from the mean expected values, the graphs show the 2.5, 10, 20, 80, 90 and 97.5 percentiles. For the indexation panels, the result for a pure nominal pension is also shown for comparison. This "nominal" line expresses the maximum benefit cuts in an average inflation environment (of 3 per cent wage inflation per year). Furthermore, these indexation panels present a price-indexed pension. This "inflation-proof" line expresses the benefit cuts that eliminate the real wage improvement (1.1 per cent per year), but leave the spending power unaffected. Table 2 shows the mean and 2.5 per cent worst results for these key variables after 5, 10 and 20 years, as well as the standard deviation of the annual changes in contributions. ${ }^{18}$

\section{Base variant without FTK requirements}

The Dutch pensions industry has voiced many complaints about the initially strict requirements imposed by FTK, especially the proposed limitation of the recovery period to only 1 year in case of underfunding (nominal funding ratio below 105

${ }^{18}$ Negative contributions are set to zero when calculating the standard deviation. 
Jacob A. Bikker and Peter J.G. Vlaar Conditional Indexation in Defined Benefit Pension Plans
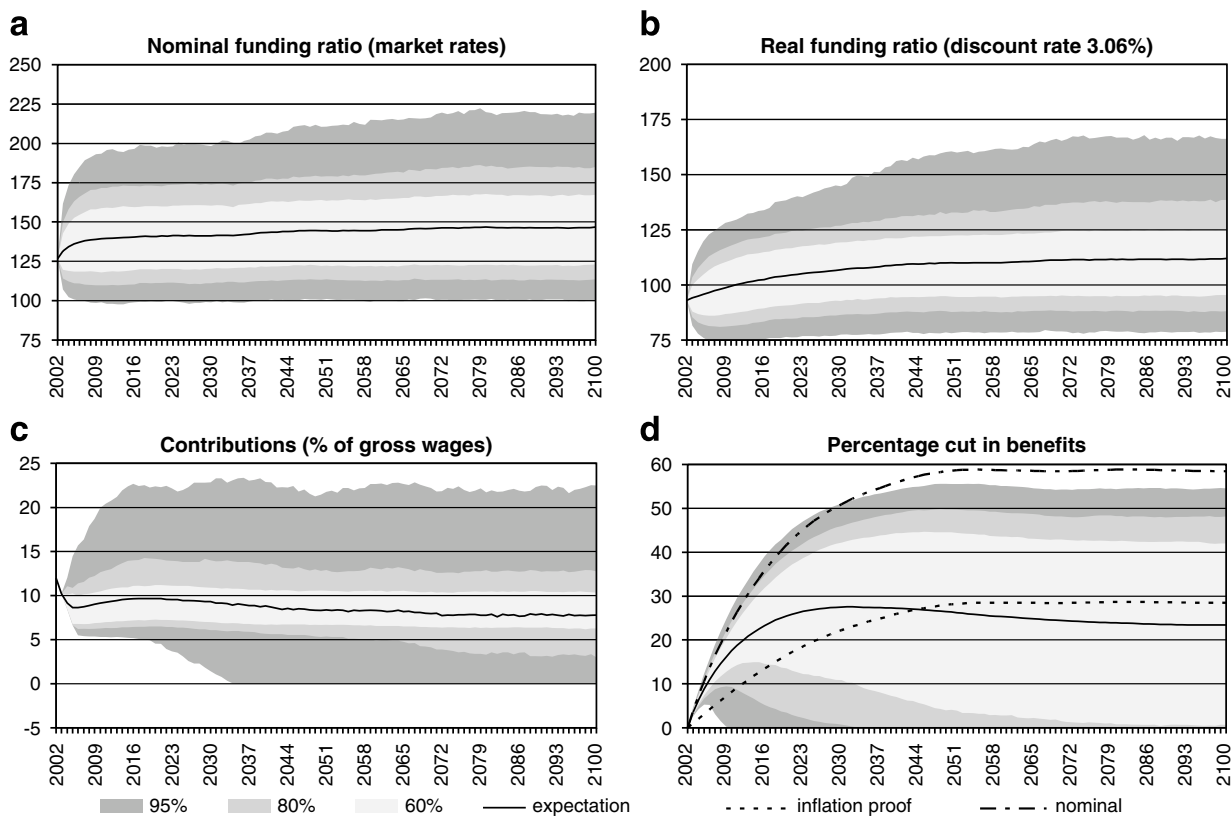

Figure 2. No official indexation ambition, contributions based on nominal term structure.
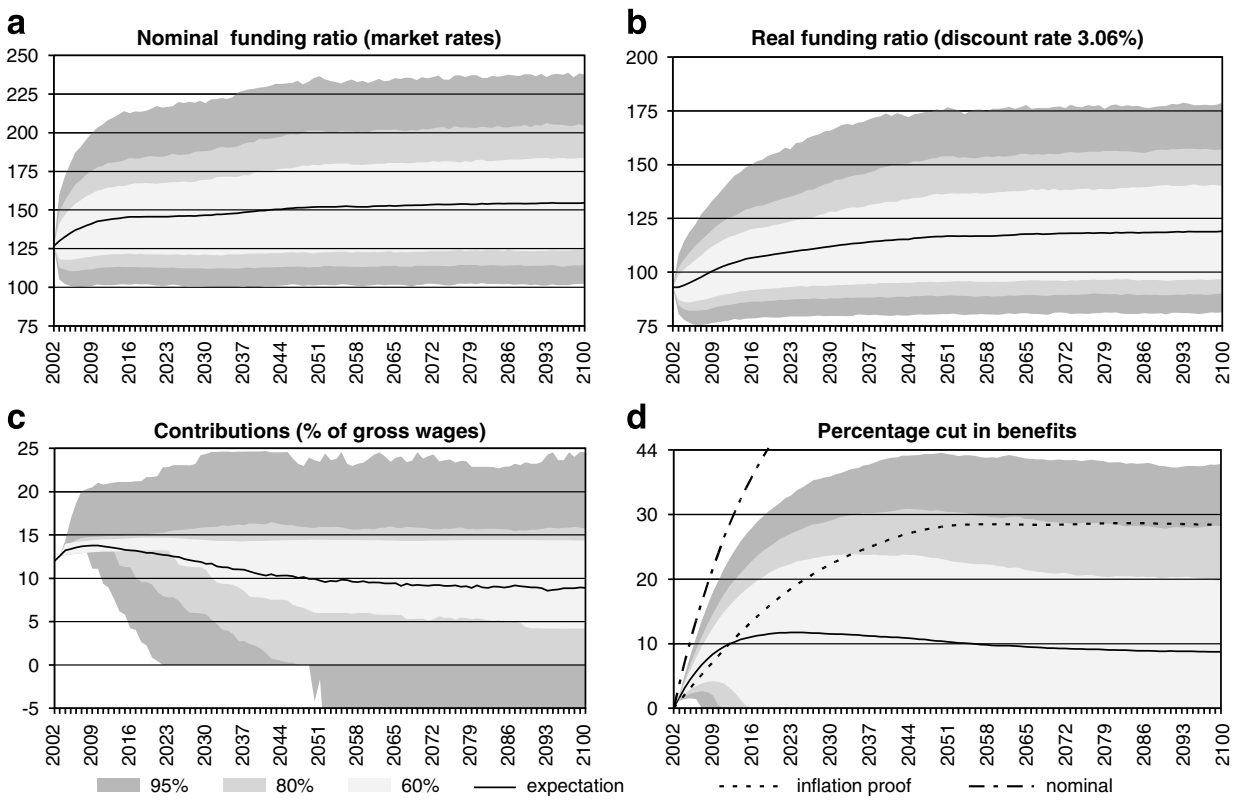

Figure 3. Conditional indexation, no earmarked reserves. 

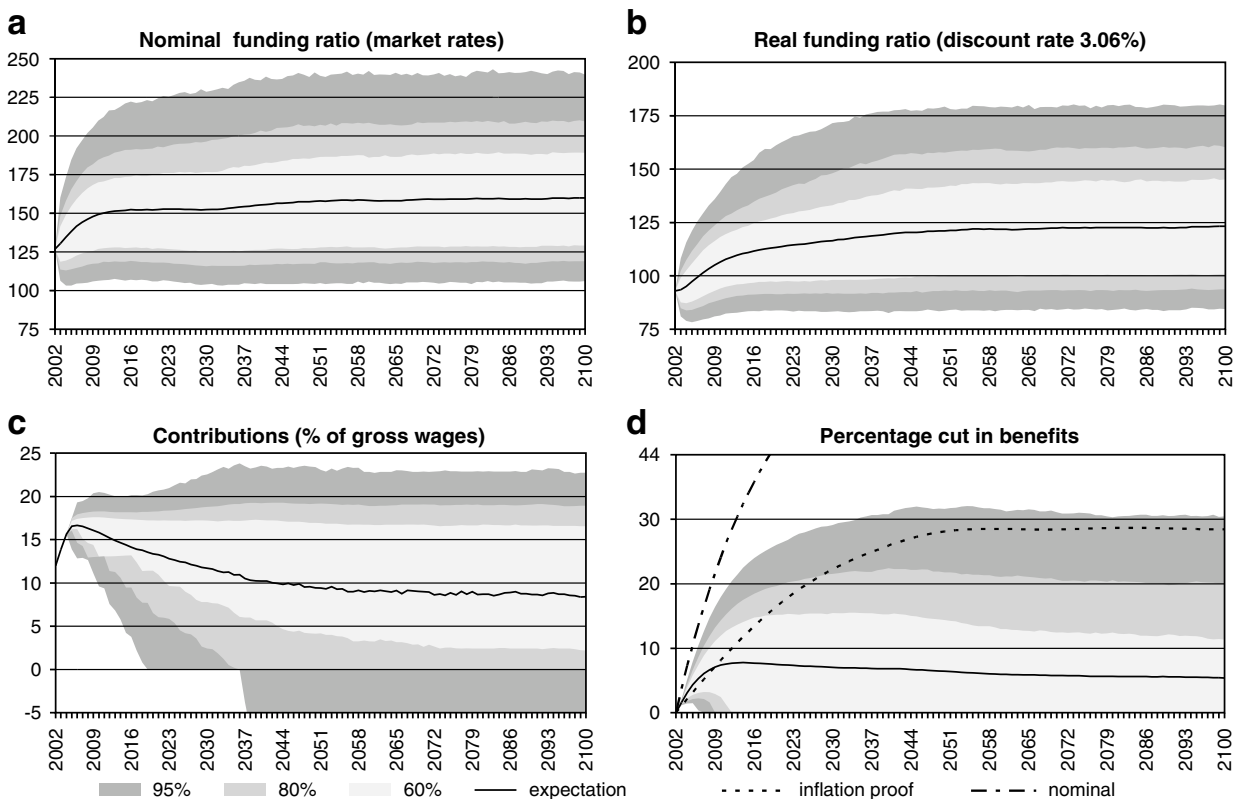

Figure 4. Conditional indexation, voluntary provisioning.
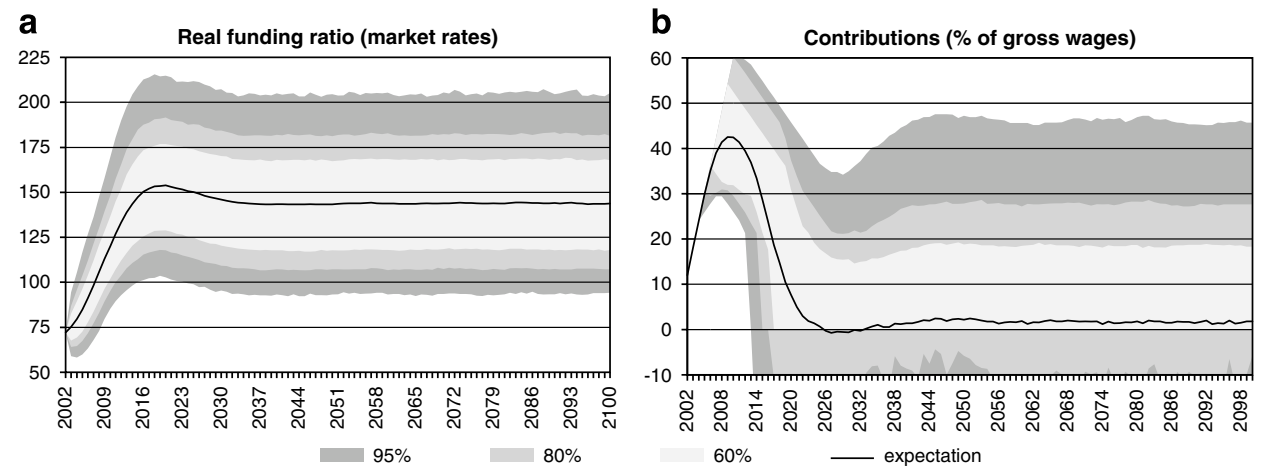

Figure 5. Unconditional indexation, no mark-up.

per cent). This requirement is said to make any nominal mismatch unacceptably risky, leaving little room to pursue an investment policy aimed at higher investment returns to secure indexation. In order to test this hypothesis, we first show results for a benchmark version of Palmnet. This first benchmark variant, referred to as the "base variant" or "Variant 1", does not take the FTK requirements into account. The baseline version of Palmnet uses a fixed discount rate equal to expected long-run real returns (3.06 per cent) to calculate liabilities and contributions. The fixed discount rate method better exploits the long-term perspective of pension funds, leading to less volatility and lower cost. ${ }^{19}$ The pension fund's policy is aimed at realising its long-term 
Table 2 Average and unfavourable simulation results for key variables

\begin{tabular}{|c|c|c|c|c|c|c|c|c|c|c|c|c|c|c|}
\hline \multicolumn{15}{|l|}{ Percentages } \\
\hline & & \multicolumn{4}{|c|}{ Contributions } & \multicolumn{3}{|c|}{ Indexation $\mathrm{cut}^{\mathrm{a}}$} & \multicolumn{3}{|c|}{ Nominal funding ratio $^{\mathrm{b}}$} & \multicolumn{3}{|c|}{ Real funding ratio $^{\mathrm{b}}$} \\
\hline & & & Level & & Vol. & & & & & & & & & \\
\hline \multicolumn{2}{|l|}{ After ... years } & 5 & 10 & 20 & & 5 & 10 & 20 & 5 & 10 & 20 & 5 & 10 & 20 \\
\hline \multicolumn{15}{|l|}{ Average results } \\
\hline 1 & Base variant & 16 & 15 & 13 & 1.3 & 6 & 8 & 8 & 144 & 151 & 151 & 102 & 109 & 113 \\
\hline 2 & Incidental indexation & 9 & 9 & 10 & 1.6 & 13 & 20 & 26 & 139 & 140 & 141 & 97 & 100 & 104 \\
\hline 3 & Indexation, no provisioning & 14 & 14 & 13 & 1.4 & 7 & 10 & 12 & 138 & 144 & 146 & 98 & 104 & 109 \\
\hline 4 & Indexation with provisioning & 17 & 15 & 13 & 1.5 & 6 & 8 & 7 & 144 & 151 & 153 & 102 & 109 & 114 \\
\hline 5 & Unconditional indexation & 39 & 39 & 3 & 4.3 & 0 & 0 & 0 & 165 & 217 & 239 & 98 & 133 & 152 \\
\hline \multicolumn{15}{|c|}{$2.5 \%$ worst-case scenarios } \\
\hline 1 & Base variant & 19 & 19 & 20 & & 13 & 21 & 28 & 104 & 106 & 103 & 79 & 82 & 81 \\
\hline 2 & Incidental indexation & 16 & 21 & 23 & & 19 & 32 & 46 & 100 & 98 & 98 & 74 & 73 & 76 \\
\hline 3 & Indexation, no provisioning & 20 & 21 & 23 & & 14 & 23 & 33 & 100 & 102 & 101 & 75 & 78 & 79 \\
\hline 4 & Indexation with provisioning & 19 & 20 & 21 & & 13 & 20 & 27 & 105 & 107 & 107 & 80 & 83 & 84 \\
\hline 5 & Unconditional indexation & 42 & 60 & 42 & & 0 & 0 & 0 & 118 & 155 & 162 & 68 & 93 & 101 \\
\hline
\end{tabular}

${ }^{a}$ The accumulation of annual cuts relative to a fully wage-indexed pension;

${ }^{b}$ Assets expressed as a percentage of the required pension provisions in, respectively, nominal and real terms. In the first four variants, the required pension provisions in real terms are calculated using a fixed discount rate of 3.06 per cent, whereas in the last variant the actual real interest rate is used. The nominal funding ratio is always computed using the actual nominal interest rate. 
506

indexation ambitions, which is reflected in a real funding ratio target of 110 per cent. The nominal funding ratio only affects the indexation policy (no indexation below 105 per cent), but has no impact on the contribution policy.

The model simulations make it clear that pension contributions initially rise from 12 per cent in 2002 to an average of 16.5 per cent in 2005, in order to repair the buffer capital (see Figure 1, Panel c). The average real funding ratio increases from 93 per cent in 2002 to its target level of 110 per cent in 2014, and thereafter continues a gradual rise up to about 121 per cent (Panel b). ${ }^{20}$ Because returns generated by the enlarged buffer capital contribute to further funding, average contributions may be permitted to come down gradually, in the course of a few decades, to less than 9 per cent. Contributions to the median fund (not shown), ${ }^{21}$ however, decline to 13 per cent rather than 9 per cent. This asymmetry is caused by the fact that substantial contribution refunds take place when the real funding ratio exceeds 175 per cent. Unforeseen developments in capital markets (with respect to stock prices and bond rates) may cause real-world contributions to deviate substantially from their expectation. There is a small chance of contributions remaining high (e.g., at least 18.7 per cent with, according to the simulation results, 10 per cent probability) or even increasing (to more than 21.2 per cent with 2.5 per cent probability). Contribution volatility (Table 2), is about 1.3 per cent, implying that a solid funding position may quickly deteriorate.

During the initial years, indexation is cut because of insufficient capital buffers (Figure 1d). The average benefit level comes out up to 7.8 per cent lower than it might have been without indexation cuts. Dispersion, however, is huge: the long-term probability of no cuts being applied at all is about 52 per cent, but there also is a 10 per cent chance of accumulated cuts deeper than 23 per cent and a 2.5 per cent chance of over 34 per cent cuts. The problem is, moreover, that the need to cut indexation arises especially when inflation becomes unexpectedly high. Compared to the benchmark of an inflation-indexed pension (real wages are expected to increase 1.1 per cent annually), the average indexation result for this pension fund is better from 2009 on. In the simulations of 20 and 10 per cent worst-case scenarios, this is only the case after, respectively, 2019 and 2033.

The probability of the nominal funding ratio (Panel a) sliding off below 105 per cent is never above 3.8 per cent. This result suggests that the strict nominal solvency requirements of the FTK are hardly necessary for pension funds with serious indexation ambitions. However, one should be aware that these relatively good results are based on correct investment return assumptions. As the continued use of the 4 per cent actuarial rate in the Netherlands shows, a fixed rate method bears the risk that too optimistic return assumptions are maintained in an environment changing unfavourably.

\footnotetext{
${ }^{20}$ The average real funding ratio is above target within 15 years due to the fact that adverse conditions may lead to an immediate increase in contributions, whereas decreases in contributions are only allowed after the target is attained. The median real funding ratio is still at 109.6 per cent after 15 years.

${ }^{21}$ The median fund is the 50th percentile of the distribution of simulation results with respect to the key variable "contributions".
} 


\section{Policy of no indexation ambition}

Variant 2 describes pension funds without official indexation commitments, and thus without any obligation to provide funding earmarked for indexation. Indexation will be given however, the funding ratio permitting, on a case-by-case basis. In this "incidental indexation" variant, there is no voluntary provisioning, nor any indexation mark-up on the contribution. The variant is based on the market valuation principle, with the current nominal interest rate term structure used to determine contributions. The use of a fixed discount rate or smoothed historical interest rates or investment returns to determine contributions is not formally ruled out for this class, but it would not be realistic to allow a mark-up on the discount rate for such threadbare schemes. The fact, moreover, that the nominal liabilities are guaranteed makes a mark-up less attractive, because a higher discount rate would increase the risk of nominal underfunding to an excessive level.

No indexation is given if required reserves are not sufficient, that is, if the nominal funding ratio is below 124.5 per cent. Above it, some indexation is given, up to full wage indexation if the real funding ratio (discounting against 3.06 per cent) is 120 per cent. Above this funding level, compensation for previous cuts relative to a full wagelinked pension, is given as well. After all previous indexation cuts are compensated, contributions may be reduced according to the policy ladder in Table 1. Indexation may be financed partly from surplus returns on investments, since expected returns exceed the nominal interest rate. Even if we take the returns on the capital buffer into account as well, such a fund can hardly be expected to provide even inflation-proof pensions without levying extra contributions however.

Figure 2 shows the results for this incidental indexation variant. As the costcovering contribution level for this nominal contract is only 8.2 per cent, on average, contributions are even allowed to fall initially (Panel c). Also, in the long run, contributions are within the relatively narrow range of 6.4-10.4 per cent for 60 per cent of the simulations. However, this does not mean that contributions are very stable over time, as the standard deviation of annual changes is 1.6 per cent, whereas it was 1.3 per cent for the base variant (see Table 2). There are two reasons for this instability. First, the cost-covering contribution itself is quite volatile (standard deviation of 1.1 per cent), as it depends on the actual nominal term structure of interest rates. Second, due to the relatively low contributions, the financial position of the pension fund is not improving substantially. Therefore, the implicit buffers of the fund to withstand a sudden drop in interest rates or a stock market crash are relatively small, and nominal underfunding remains a serious threat (about 4.3 per cent probability). The assumed 1-year recovery terms thus sometimes lead to very high contributions, even though a maximum increase of 10 percentage points of the contribution base was assumed to model the allowance for tailor-made solutions. Hence, the FTK requirements may cause real pain to ambitionless pension funds.

The moderate initial contribution levels reflect the absence of indexation ambitions. Naturally, there is a downside to this: even apart from the greater probability of nominal underfunding, average benefits lag far behind wage developments with cumulated cuts of more than 25 per cent, on average (Figure 2d). In worst-case scenarios, indexation cuts are even almost as severe as they would have been under a 
merely nominal pension scheme in an average inflation scenario (a 3 per cent cut every year). In the worst 2.5 per cent of scenarios, for instance, cuts after 10 and 20 years cumulate to 32 and 46 per cent, respectively.

\section{Conditional indexation without voluntary provisioning}

An explicit indexation objective offers participants more certainty with respect to indexation. Variant 3 presents the simulation effects of pension fund policy with a wage indexation ambition. The variant shows the impact of a fund that only follows the minimum requirements of the FTK. That is to say, the cost-covering contribution rate is made in accordance with the indexation ambition. Shortfall contributions are levied in response to too low nominal funding ratios, in line with FTK requirements, as in Variant 2. There are no voluntary shortfall contributions in response to too low real funding ratios, however, as would be expected in the case of more serious indexation ambition. The pension fund does not actively build up an earmarked provision for indexation. In normal times, the higher contributions should still be sufficient to build up capital funding for indexation. However, especially if inflation is high, nominal interest rates are likely to be high as well, and adequate funding for guaranteed nominal rights, including buffers, might not be sufficient to also safeguard indexation. High indexation might quickly deplete resources in this case as liabilities are not likely to be fully funded in real terms.

The variant is based on a 3.06 per cent fixed discount rate to determine pension contributions and the real funding ratio. Since this rate is below the nominal market rate, break-even contributions in this scenario are also higher, at about 13 per cent. Therefore, in contrast to the previous ambitionless variant, average pension contributions initially increase from 12 to 13.8 per cent (see Figure 3, Panel c). This is slightly higher than the break-even contribution, as in the short run a nominal funding ratio below 124.5 per cent is more likely than a real funding ratio above 120 per cent. Eventually, buffers are larger than in the previous variant, with the real funding ratio increasing to 118 per cent, on average (Panel b). As a consequence, average contributions can be allowed to drop to, in the long run, 9 per cent because the larger capital buffers lead to larger returns on investment. This equilibrium contribution level is very similar to the baseline scenario (Variant 1). Contribution volatility is 1.4 per cent, so less than in the previous scenario, but higher than in the pre-FTK baseline (Table 2).

With respect to indexation (Figure 3, Panel d), the average cut in benefits will be at most 11.7 per cent, which is 4 percentage point higher than in the baseline scenario, but much better than the 28 per cent in the incidental indexation variant. Dispersion is again huge, however. In the long run, the probability of a fully wage-linked pension is about 45 per cent, but in the 2.5 per cent worst-case scenarios the benefits are at most 62 per cent of the targeted amount. The fact that real underfunding does not necessarily lead to extra contributions also implies a relatively high probability (of about 3.8 per cent) of a nominal funding ratio below 105 per cent. The 1-year trajectory may lead to soaring contributions, for instance over 24 per cent of gross wages in the worst 2.5 per cent of the scenarios. 


\section{Conditional indexation with provisioning}

A pension fund that has a more serious indexation ambition than in the previous variant will actively seek to reserve funds for indexation. However, neither the desired size of the earmarked reserves nor the manner in which they should be built up have been regulated. We assume that the target real funding ratio is 110 per cent and in case of insufficient reserves, a 15-year recovery plan is triggered (see the policy ladders from Table 1). The same assumptions were used in the base variant. In most cases, a recovery policy will be triggered by a real funding ratio below target. However, in a low inflation environment (with, hence, low interest rates) the nominal funding ratio may pose stricter constraints.

Comparing Figure 4 with Figure 1, it is clear that the impact of the FTK on a pension fund with a serious, although conditional, indexation ambition is relatively small. With respect to contributions (Panel c), the expectation is almost the same, but contributions under the FTK regime are somewhat higher in unfavourable scenarios. For the 90 and 97.5 percentiles, the difference is, respectively, 0.3 and 1.7 percentage points. These higher extremes are due to the relatively strict recovery rules in case of nominal underfunding ( 2.4 per cent probability). This also increases the volatility of the contributions somewhat to 1.5 per cent. The stricter policy has a clear advantage on the benefit side. In the long run, even in the 2.5 per cent worst scenarios the benefit cut is just over 31 per cent (Figure 4, Panel d), whereas it was almost 34 per cent in the baseline scenario (Figure 1, Panel d) and 38 per cent in the no-provision scenario (Figure 3, Panel d).

So the additional FTK requirements, in particular the 1-year nominal underfunding recovery term, turn out to cause little trouble to funds that take indexation ambitions seriously. ${ }^{22}$ Only in the 2.5 per cent worst cases, contributions are more extreme. This seems to be an acceptable price for the higher probability of indexation and increased protection for unconditional rights. In this simulation, the real funding ratio is again based on a fixed discount rate. The danger inherent to this choice is that when a decline in interest rates and stock yields turns out to be permanent, return assumptions remain the same, thereby becoming overoptimistic. The present variant limits this risk to some extent in that it takes a market valuation approach to the nominal funding ratio. Therefore, at least the unconditional pension rights cannot be endangered by overoptimistic return assumptions. This is especially important as sustained contribution levels above cost-covering level endanger the continuity of the fund since the implicit intergenerational transfers are unfavourable for new entrants. This effect is not modelled here, however.

\section{Unconditional indexation}

The last variant assumes unconditional full wage indexation. As indexation is unconditional, the solvency tests for this fund are applied to the real funding ratio,

\footnotetext{
${ }^{22}$ In the U.K., the 1-year recovery prescriptions in case of underfunding were relaxed in March 2002 to a 3year term. The definition of underfunding is different though. The critical real funding ratio (with a maximum inflation compensation of 5 per cent) should be at least 90 per cent. In the U.S., it is even allowed to amortise a shortfall over 30 years, although a shortening to 18 years has been proposed.
} 
based on a discount rate equal to the actual real market interest rate. Contribution policy is based on a fixed discount rate of 2 per cent, equal to the average discount rate used for the calculation of the real funding ratio. As indexation cuts cannot be used to alleviate financial deficiencies, the maximum contribution boundary is doubled to 100 per cent of the contribution base in this variant.

Initially, application of FTK rules lead to a prolonged period of maximum contribution rises (10 per cent of the base) as the real funding ratio should be at least 105 per cent (Figure 5, Panel b). Average contributions continue to rise to reach a level of 42 per cent in 2009. In adverse scenarios, the contribution even increases to the maximum level of about 60 per cent of gross wages. These very high contributions lead to an average real funding ratio of 144 per cent ( 219 per cent in nominal terms), even though contribution holidays are allowed at a real funding ratio of 140 per cent and restitutions take place starting at 175 per cent. As these real funding ratios are calculated against a discount rate of on average 2 per cent, whereas the expected real return on the asset portfolio is over 3 per cent, the average contribution level drops to almost zero. However, with 10 per cent probability, contributions remain above 28 per cent and with 2.5 per cent probability, even over as high as 46 per cent. The likelihood of benefit cuts is nil, as guaranteed.

This variant illustrates how the FTK requirements to redress underfunding within the year and to value guaranteed pension rights on "certainty" market base, turn full unconditional indexation into a (practically) untenable proposition without seriously adjusting the asset mix of the fund. This is caused by the volatility of real interest rates (the standard deviation being some 60 basis points per annum), which leads to strong fluctuations in liabilities over time. Reducing the mismatch between assets and liabilities might alleviate this problem somewhat, but would certainly not eliminate it completely. Even if the fund could hold an exactly replicating portfolio (which at the moment is not possible due to the absence of wage-indexed bonds), substantial contribution volatility would remain as the market-based contribution is very sensitive to real interest rate changes. ${ }^{23}$

\section{Selected overall results}

From the overview in Table 2, it is clear that two variants deviate strongly from the rest in terms of contributions and indexation. One is Variant 2, representing a pension scheme without official indexation ambition. Excess returns cannot be expected to be high enough on average to offer a substantial indexation level. Moreover, poor returns on investment or declining interest rates will cause severe contribution rises even in this variant, as a result of nominal underfunding. The other deviating variant is number 5, with unconditional indexation. Initially, huge contributions are required to realise this ambition. Thanks to the capital buffers thus built (the real funding ratio grows, after 10 years, to 131 per cent, given a 2 per cent expected discount rate), contributions may eventually fall far below the levels seen in the other simulations. Yet, under

\footnotetext{
${ }^{23}$ In case of market valuation, the standard deviation of annual changes in the market-based cost-covering contribution is 2.6 per cent of gross wages.
} 
unfavourable conditions (low returns on investments or low interest rates), contribution rates remain extremely high. Cuts in real term commitments are ruled out in this variant, in line with the unconditional nature of its indexation.

The typical pension contract in the Netherlands offers conditional wage indexation. This is modelled in Variants 1, 3 and 4. In these variants, relatively high initial average pension contributions are needed to build up capital buffers. After more than 15 years, average pension contributions come down substantially and low contributions may suffice, owing in part to the returns on the large capital buffer. At the same time, there is a low probability of continued high or even rising contributions. After incomplete indexation in the early years, the probability of benefit cuts in later years is commonly very low. Thus, in the long run, the degree of pension security is very reasonable, reflecting that most of our simulations present pension fund policies that take indexation seriously. This attitude has been translated into a "sufficient" mark-up on contributions. If investment returns are relatively low however, substantial cuts are still possible.

On average, the differences between the three conditional indexation variants are only minor. Not provisioning for indexation leads to somewhat lower initial contribution increases. This comes at the cost of higher benefit cuts, especially in adverse scenarios, and a higher probability of nominal underfunding, leading to more volatile and more extreme contribution levels. In case of active provisioning for conditional rights (Variant 4), the 1-year recovery plans are much less problematic.

\section{Conclusions}

This paper presents illustrative simulations of indexation policies with varying degrees of ambition, using the ALM model Palmnet. These simulations provide an understanding of the average expected development of pension contributions, benefit cuts and funding ratios, but also of the dispersion of these variables, thus sketching the outcomes of unfavourable scenarios. The main conclusions are as follows.

As regards transparency, a major improvement is that pension funds have to inform their participants in explicit terms about their indexation ambitions. The likelihood of indexation must be determined on the basis of a continuity analysis. Our analysis shows that the content of this information would be inadequate if the emphasis is only on long-term average values of the key variables. Differences between pension fund policies become most clear in the worst-case scenarios. Hence, adequate information should include - stylised facts of - the future distribution of the key variables.

The question whether the minimum FTK requirements concerning conditional indexation offer sufficient assurance that a fund's ambition will be realised can be answered in the affirmative. Despite the fact that provisioning for conditional commitments has not been made mandatory, indexation cuts turn out to remain fairly limited, although still substantial in adverse circumstances. On the one hand, this is because cost-covering contributions as defined under FTK do include a surcharge for conditional indexation. On the other, it is because of the occasionally very high contributions due to a one-off nominal underfunding. It turns out that pension funds that intend to provide indexation with minimum effort (read: minimum 
contributions), so that voluntary indexing reserves may fail to materialise, are more risk-prone in the sense that these funds run a much greater risk of nominal underfunding, incidentally leading to soaring contribution rises. If no surcharges to the contribution are levied to finance indexation, cuts will be substantial, and moreover nominal underfunding resulting in extreme contributions is hard to avoid.

The question whether FTK implies overrestrictive requirements to a pension fund offering conditional indexation can be answered in the negative. The complaint, frequently voiced by the pension industry, that the FTK - and the 105 per cent minimum funding ratio in particular - will impede indexation, because mismatching will become too risky, is not corroborated by our simulations. A pension fund that has serious indexation ambitions should build up earmarked indexation reserves. That will make the risk of underfunding relatively low, even assuming the current investment mix of 50 per cent equities.

For pension funds offering an indexation guarantee, the simulation outcomes are unfavourable. Under FTK, realisation of unconditional indexation will be far more difficult, because very large implicit capital buffers need to be shored up. Further, such buffers are also extremely sensitive to movement in the real interest rate. For instance, the 16-year interest rate of 3.8 per cent in 2005 implied a discount rate of just 0.8 per cent. As a consequence, as long as underfunding can only be dealt with by contribution rises, extreme levels are hardly avoidable. The volatility in the funding ratio might be reduced by improving the match of investment portfolio and liabilities, but only to a limited extent, as wage-indexed bonds are yet unavailable and as the market-based contribution is also sensitive to real interest rate changes.

All in all, our simulation analyses show that conditional DB pension plans can provide a reasonable insurance against wage or price inflation, even where full guarantees are fairly unattainable. Further, they illustrate the tenability of conditional DB pension plans under ageing, the new fair-value accounting regimes, and possible volatility on financial markets. However, important preconditions for this result, that have been taken for granted in this study, are that the fund will always survive, and that the number of new entrants is not affected by the contribution level. If contribution levels are likely to be too far above cost-covering level for sustained periods, these conditions may no longer be realistic. We leave the relative attractiveness of conditional DB systems compared to individual DC systems for future research.

\section{References}

Blake, D. (2000) 'Does it matter what type of pension scheme you have?', Economic Journal 110(461): 46-81. Boenders, C.G.E. (1997) 'A hybrid simulation/optimisation scenario model for asset/liability management', European Journal of Operational Research 99: 126-135.

Davis, E.P. (2004) 'Is there a pension crisis in the UK?', The Geneva Papers on Risk and Insurance - Issues and Practice 29: 343-370.

Duffee, G.R. (2002) 'Term premia and interest rate forecasts in affine models', Journal of Finance 57(1): 405-443.

Duffie, D. and Kan, R. (1996) 'A yield factor model of interest rates', Mathematical Finance 6: 379-406.

Harvey, A.C. (1989) Forecasting Structural Time Series Models and the Kalman Filter, Cambridge, UK: Cambridge University Press. 
Ponds, E.H.M. (2003) 'Pension funds and value-based generational accounting', Journal of Pension Economics and Finance 2: 295-325.

Sharpe, W.F. (1976) 'Corporate pension funding policy', Journal of Financial Economics 3: $183-193$.

Summers, L.H. (1983) 'Observations on the indexation of old age pensions', in Z. Bodie and J.B. Shoven (eds) Financial Aspects of the United States Pension System (NBER-PR), Chicago: The University of Chicago Press.

Van Ewijk, C., Kuipers, B., ter Rele, H., van de Ven, M. and Westerhout, E. (2000) Ageing in the Netherlands, The Hague: CPB/Sdu Publishers.

Van Rooij, M.C.J., Siegmann, A.H. and Vlaar, P.J.G. (2004) Palmnet: A pension asset and liability model for the Netherlands, DNB Research Memorandum WO no. 760 (www.dnb.nl).

Vlaar, P.J.G. (2005) Defined benefit pension plans and regulation, DNB Working paper no. 63 (www.dnb.nl).

Wilkie, A.D. (1986) 'A stochastic investment model for actuarial use', Transactions of the Faculty of Actuaries 39: 341-403.

Wilkie, A.D. (1995) 'More on a stochastic investment model for actuarial use', British Actuarial Journal 1: $777-964$.

\section{Appendix: Palmnet's inflation and interest rate block}

Long-term interest rates in the model are based on an affine two-factor term structure model. ${ }^{24}$ The determining variables are the short-term interest rate and expected (short-term) inflation. This model assumes a first-order vector autoregressive structure for expected inflation and 3-month interest rates. The model is heteroscedastic in the sense that volatility is rising with the level of inflation or interest rates. This way, it is guaranteed that nominal interest rates cannot become negative. The same heteroscedasticity structure is used in all model equations in order to preserve the affine (i.e., linear) term structure relationship without having to rely on independence between shocks to inflation and interest rates. Longer term interest rates are a linear function of future short-term interest rates and the price of risk. The former follow directly from the current short-term interest rate and expected inflation, whereas the latter is determined by the covariance of the pricing kernel with expected inflation and short-term interest rates, respectively. The model is calibrated on quarterly data for Germany. We use German data as these are most representative for the euro system's monetary policy, which is relevant for the interaction between interest rates and inflation. The quarterly frequency of two-factor term structure model (as opposed to the annual frequency of the rest of Palmnet) is used: first, to increase the number of observations; second, to be able to perform simulations with smoothed interest rates and third, to reduce the probability that short-term interest rates become negative.

In principle, the model for inflation and short- and long-term interest rates can be estimated simultaneously. However, it turns out that the expected time-series behaviour of short-term interest rates and expected inflation, according to the term structure of interest rates, is not the same as the one actually observed in the past. As we simulate over a forecast horizon of 100 years, including proper time-series

\footnotetext{
${ }^{24}$ Duffie and Kan (1996); Duffee (2002).
} 
parameters is most important. Therefore, a four-step procedure was used instead. In the first step, the dynamics of short-term interest rates $\left(i^{s}\right)$ and (short-term) expected inflation $\left(\pi^{e}\right)$ is estimated, using a Kalman filter approach ${ }^{25}$ to decompose actual inflation into expected inflation, surprise inflation and seasonal patterns. This is done on quarterly data from 1960-I until 2004-II:

$$
\begin{aligned}
& {\left[\begin{array}{c}
i_{t}^{s} \\
\pi_{t}^{e}
\end{array}\right]=} {\left[\begin{array}{l}
\bar{i}^{s} \\
\bar{\pi}^{e}
\end{array}\right]+\left[\begin{array}{rr}
0.90 & 0.11 \\
-0.00 & 0.95
\end{array}\right]\left[\begin{array}{cc}
i_{t-1}^{s} & -\bar{i}^{s} \\
\pi_{t-1}^{e} & -\bar{\pi}^{e}
\end{array}\right] } \\
&+\sqrt{0.03 i_{t-1}^{s}+0.15 \pi_{t-1}^{e}}\left[\begin{array}{c}
\varepsilon_{t}^{i} \\
\varepsilon_{t}^{\pi}
\end{array}\right], \\
& {\left[\begin{array}{c}
\varepsilon_{t}^{i} \\
\varepsilon_{t}^{\pi}
\end{array}\right] \sim N\left(\left[\begin{array}{l}
0 \\
0
\end{array}\right],\left[\begin{array}{ll}
1 & 0.27 \\
0.27 & 0.59
\end{array}\right]\right) }
\end{aligned}
$$

where $\left(\overline{i^{s}}\right)$ and $\bar{\pi}^{e}$ represent sample averages.

In the second step, the covariances of the pricing kernel with shocks to the shortterm interest rate and expected inflation are estimated, given the estimated parameters and the optimal prediction of expected inflation from the first step. Hereby, the measurement errors of the bonds of different maturities are allowed to be correlated. The measurement errors represent factors in longer term yields that are independent from inflation and short-term rates. For instance, long-term interest rates in Europe are, at least in the short run, influenced by bond returns in the U.S.

In the third step, these measurement errors are examined. It turns out that they are indeed highly correlated, both cross-sectionally and over time. The measurement errors are very similar for all maturities, although slightly bigger for longer ones. Therefore, we decided to model longer term yields as the yield following from the term structure model plus a measurement error that is identical for all maturities, apart from a scaling factor. This measurement error follows a first-order autoregressive process with an AR(1)-parameter of 0.9 .

Finally, we deal with the problem that the time-series pattern of the past need not be representative for the future. For instance, the average inflation rate over the sample was 3 per cent, whereas, for the future, 1.9 per cent is assumed. For the short rate, an equilibrium value of 4.2 per cent is supposed. Moreover, the volatility of interest rates and inflation in the 1970s was much higher than in recent times. Therefore, we rescaled volatilities of inflation and short rates to 55 per cent of historical values. The volatility of innovations to the long-term measurement errors was calibrated at 85 per cent of the short-rate volatility, in accordance with results for the last 20 years. In order to remain a reasonable fit for long-term rates, the covariances with the kernel are adjusted somewhat as well, such that the fit for 2003 was reasonably good.

\footnotetext{
${ }^{25}$ Harvey (1989).
} 


\section{About the Authors}

Jacob A. Bikker is a senior researcher at the Strategy Department, Supervisory Policy Division, De Nederlandsche Bank (DNB). His research interests are on banking, insurance and pensions, financial conglomerates, risk management, competition and efficiency, and procyclicality and regulation. Before joining the Supervisory Policy Division in 1997, he was unit head research at the European Monetary Institute (the predecessor of the European Central Bank) in Frankfurt am Main. He had various positions at the Vrije Universiteit in Amsterdam. Recent publications on pensions are Bikker, J.A., Spierdijk, L. and van der Sluis, P.J. (2007), 'Market impact costs of institutional equity trades', Journal of International Money and Finance, and Bikker, J.A. and de Dreu, J. (2007) 'Operating costs of pension funds: The impact of scale, governance and plan design', Journal of Pension Economics and Finance 6(3): 1-27.

Peter Vlaar is a senior researcher at the Financial Research Department, Economics and Research Division, De Nederlandscha Bank (DNB) and senior researcher at Netspar. His main research interests are pension economics, financial economics and econometrics. Before joining the Central Bank in 1994, he was affiliated with Maastricht University. Recent publications include Vlaar, P.J.G., (Forthcoming) 'GDP growth and currency valuation: The case of the dollar', Journal of International Money and Finance, and den Reijer, A.H.J. and Vlaar, P.J.G. (2006) 'Forecasting inflation: An art as well as a science!', De Economist 154(1): 19-40. 